\title{
Time fractional problem via inner product including weighted function
}

\author{
Süleyman ÇETINNKAYA ${ }^{1 *}$, Ali DEMİR ${ }^{1}$ \\ ${ }^{1}$ Kocaeli Üniversitesi, Fen-Edebiyat Fakültesi, Matematik Bölümü, İzmit, Kocaeli \\ Geliş Tarihi (Received Date): 10.01.2021 \\ Kabul Tarihi (Accepted Date): 02.08.2021
}

\begin{abstract}
In this research, we discuss the construction of analytic solution of homogenous initial boundary value problem including PDEs of fractional order. Since homogenous initial boundary value problem involves Caputo fractional order derivative, it has classical initial and boundary conditions. By means of separation of variables method and the inner product defined on $L^{2}[0, l]$, the solution is constructed in the form of a Fourier series with respect to the eigenfunctions of a corresponding Sturm-Liouville eigenvalue problem including fractional derivative in Caputo sense used in this study. We defined a new inner product with a weighted function to get coefficients in the Fourier series. Illustrative example presents the applicability and influence of separation of variables method on fractional mathematical problems.
\end{abstract}

Keywords: Caputo fractional derivative, dirichlet boundary conditions, separation of variables, spectral method, weighted inner product

\section{Ağırlıklı iç çarpım ile zaman kesirli problem}

Öz

$\mathrm{Bu}$ çalışmada, kesirli mertebeden kısmi diferansiyel denklemler içeren homojen başlangıç sınır değer probleminin analitik çözümünü araştırlyoruz. Homojen başlangıç sınır değeri problemi Caputo kesirli mertebe türevini içerdiğinden klasik başlangıç ve sınır koşullarına sahiptir. Değişkenlerine ayırma yöntemi ve $L^{2}[0, l]$ de tanımlanan ağırlıklı iç çarpım ile çözüm, bu çalışmada kullanılan Caputo anlamında kesirli türevi içeren bir Sturm-Liouville özdeğer probleminin özfonksiyonlarına göre bir Fourier

\footnotetext{
* Süleyman ÇETINKAYA, suleyman.cetinkaya@kocaeli.edu.tr, http://orcid.org/0000-0002-8214-5099 Ali DEMİR, ademir@kocaeli.edu.tr, http://orcid.org/0000-0003-3425-1812
} 
serisi şeklinde oluşturulmuştur. Fourier serisindeki katsayıları elde etmek için ağırlıklı fonksiyona sahip yeni bir iç çarpım tanımlanmıştır. Çözülen örnek, değişkenlerine ayırma yönteminin kesirli matematik problemleri üzerindeki uygulanabilirliğini ve etkisini göstermektedir.

Anahtar kelimeler: Caputo kesirli türev, dirichlet sınır koşullarl, değiş̧kenlerine ayırma, spektral method, ăğrlıklı iç çarpım

\section{Introduction}

As PDEs of fractional order plays an influential role in mathematical models of processes in various branches of science such as applied mathematics, physics chemistry etc., the interest of this topic increases enormously. Because of non-local property of fractional derivative, the model with fractional derivative for physical problems turns out to be the best choice to analyze the behaviour of the complex non linear processes. That is why, it attracts increasing number of researchers. The derivatives in the sense of Caputo are one of the most common one since mathematical models with Caputo derivatives give better results than the analysis of ones including other fractional derivatives. This conclusion is supported by various papers [1-16]. In addition, the derivative of a constant function in Caputo sense is zero which does not hold by many fractional derivatives. The solution of fractional differential equations in the sense of Caputo derivative is obtained in terms of Mittag-Leffler function or its derivations, as a result, the Mittag-Leffler function (MLF) plays a vital role in the solutions of fractional differential equations. It takes the place of exponential function which is a significant function to form the solution of integer order differential equations [17-25].

The main goal of this study is to establish the analytic solution of following time fractional differential equations with Dirichlet boundary and initial conditions.

$D_{t}^{\alpha} u(x, t)=u_{x x}(x, t)+B u_{x}(x, t)-C u(x, t)$,

$u(0, t)=u(l, t)=0$,

$u(x, 0)=f(x) e^{-\frac{B}{2} x}$,

where $0<\alpha<1,0 \leq x \leq l, 0 \leq t \leq T, B, C \in \mathbb{R}$.

This problem models diffusion processes in terms of fractional derivative. The outcomes of this model is much more better than the outcomes of the ones including integer order derivatives, since fractional derivative is a non-local operator whereas integer order derivative is a local operator. The novelty of this research is that the solution of this fractional problem is constructed by means of seperation of variables with weighted inner product defined on $L^{2}[0, l]$ as:

$<u, v \geq \frac{2}{l} \int_{0}^{l} u(x) v(x) e^{B x} d x$

where the functions $u(x)$ and $v(x)$ belong to the function space $L^{2}[0, l]$. 


\section{Preliminary results}

In this subsection, fundamental definitions are recalled.

The $q^{\text {th }}$ order fractional derivative of $u(t)$ in Caputo sense is defined as

$D^{q} u(t)=\frac{1}{\Gamma(n-q)} \int_{t_{0}}^{t}(t-s)^{n-q-1} u^{(n)}(s) d s, \quad t \in\left[t_{0}, t_{0}+T\right]$, (4)

where $u^{(n)}(t)=\frac{d^{n} u}{d t^{n}}, n-1<q<n$. Notice that Caputo fractional derivative coincides with ordinary derivative when the order of the derivative is integer.

The $q^{\text {th }}$ order Caputo fractional derivative for $0<q<1$ is established as follows:

$D^{q} u(t)=\frac{1}{\Gamma(1-q)} \int_{t_{0}}^{t}(t-s)^{-q} u^{\prime}(s) d s$

$t \in\left[t_{0}, t_{0}+T\right]$

The two-parameters MLF which is taken into account in eigenvalue problem, is given by

$E_{\alpha, \beta}\left(\lambda\left(t-t_{0}\right)^{\alpha}\right)=\sum_{k=0}^{\infty} \frac{\left(\lambda\left(t-t_{0}\right)^{\alpha}\right)^{k}}{\Gamma(\alpha k+\beta)}, \alpha, \beta>0$,

including constant $\lambda$ Especially, for $t_{0}=0, \alpha=\beta=q$ we have

$E_{\alpha, \beta}\left(\lambda t^{q}\right)=\sum_{k=0}^{\infty} \frac{\left(\lambda t^{q}\right)^{k}}{\Gamma(q k+q)}, q>0$

MLF coincides with exponential function i.e., $E_{1,1}(\lambda t)=e^{\lambda t}$ for $q=1$. For details see $[26,27]$.

\section{Main results}

The solution of the problem (1)-(3) is established by employing the separation of variables method which leads to the following form:

$u(x, t ; \alpha)=X(x) T(t ; \alpha)$

where $0 \leq x \leq l, 0 \leq t \leq T$.

After substitution of (8) into (1) and arrangement, we have

$\frac{D_{t}^{\alpha}(T(t ; \alpha))}{T(t ; \alpha)}+C=\frac{X^{\prime \prime}(x)+B X^{\prime}(x)}{X(x)}=-\lambda$.

The related Sturm-Liouville problem is obtained as follows:

$X^{\prime \prime}(x)+B X^{\prime}(x)+\lambda X(x)=0$,

$X(0)=X(l)=0$. 
The solution of this problem is determined in terms of the exponential function in the following form:

$X(x)=e^{r x}$.

Hence the characteristic equation is computed in the following form:

$r^{2}+B r+\lambda=0$

Case 1. If $B^{2}-4 \lambda>0$, the equation (13) have two distinct real roots $r_{1}, r_{2}$. Hence the solution of Sturm-Liouville problem (10)-(11) becomes

$X(x)=c_{1} e^{r_{1} x}+c_{2} e^{r_{2} x}$.

The first boundary condition yields

$X(0)=0=c_{1}+c_{2}$,

which leads to

$c_{1}=-c_{2}$.

Similarly second boundary condition leads to

$X(l)=c_{1}\left(e^{r_{1} l}-e^{r_{2} l}\right)=0 \Rightarrow c_{1}=0, c_{2}=0$,

which implies that there is not any solution for $B^{2}-4 \lambda>0$.

Case 2. If $B^{2}-4 \lambda=0$, the equation (13) have two coincident roots $r_{1}, r_{2}$ such that $r_{1}=$ $r_{2}$. Hence the solution of Sturm-Liouville problem (10)-(11) becomes

$X(x)=c_{1} e^{r_{1} x}+c_{2} x e^{r_{2} x}$.

By making use of the first boundary condition, we have

$X(0)=c_{1}=0$

Similarly second boundary condition leads to

$X(l)=c_{2} l e^{r_{1} l} \Rightarrow c_{2}=0$,

which implies that there is no solution for $\mathrm{B}^{2}-4 \lambda=0$.

Case 3. If $B^{2}-4 \lambda<0$, the roots of characteristic equation are complex. Hence the solution of Sturm-Liouville problem (10)-(11) becomes

$X(x)=e^{-\frac{B}{2} x}\left(k_{1} \cos \left(\frac{\sqrt{4 \lambda-B^{2}}}{2} x\right)+i k_{2} \sin \left(\frac{\sqrt{4 \lambda-B^{2}}}{2} x\right)\right)$.

By making use of the first boundary condition we have

$X(0)=k_{1}=0$. 
Similarly last boundary condition leads to

$X(l)=e^{-\frac{B}{2} l} i k_{2} \sin \left(\frac{\sqrt{4 \lambda-B^{2}}}{2} l\right)=0$,

which implies that

$\sin \left(\frac{\sqrt{4 \lambda-B^{2}}}{2} l\right)=0$

which yields the following eigenvalues

$\lambda_{n}=\frac{4 w_{n}^{2}+B^{2} l^{2}}{4 l^{2}}=\frac{4 w_{n}^{2}+(B l)^{2}}{(2 l)^{2}}, n=0,1,2,3, \ldots, \lambda_{1}<\lambda_{2}<\lambda_{3}<\cdots$

where $w_{n}=n \pi,(n=0,1,2,3, \ldots)$ satisfy the equation $\sin \left(w_{n}\right)=\sin \left(\frac{\sqrt{4 \lambda_{n}-B^{2}}}{2} l\right)=0$.

As a result, the solution is obtained as follows:

$X_{n}(x)=\sin \left(w_{n}\left(\frac{x}{l}\right)\right) e^{-\frac{B}{2} x}, n=1,2,3, \ldots$

The second equation in (9) for eigenvalue $\lambda_{n}$ yields the fractional differential equation below:

$\frac{D_{t}^{\alpha}(T(t ; \alpha))}{T(t ; \alpha)}=-(C+\lambda)$

which yields the following solutions

$T_{n}(t ; \alpha)=E_{\alpha, 1}\left(-\left(C+\frac{4 w_{n}^{2}+(B l)^{2}}{(2 l)^{2}}\right) t^{\alpha}\right), n=0,1,2,3, \ldots$

The solution for every eigenvalue $\lambda_{n}$ is constructed as

$u_{n}(x, t ; \alpha)=E_{\alpha, 1}\left(-\left(C+\frac{4 w_{n}^{2}+(B l)^{2}}{(2 l)^{2}}\right) t^{\alpha}\right) \sin \left(w_{n}\left(\frac{x}{l}\right)\right) e^{-\frac{B}{2} x}, n=0,1,2,3, \ldots$,

which leads to the following general solution

$u(x, t ; \alpha)=\sum_{n=1}^{\infty} A_{n} e^{-\frac{B}{2} x} \sin \left(w_{n}\left(\frac{x}{l}\right)\right) E_{\alpha, 1}\left(-\left(C+\frac{4 w_{n}^{2}+(B l)^{2}}{(2 l)^{2}}\right) t^{\alpha}\right)$.

Note that it satisfies boundary condition as well as fractional differential equation. The coefficients of general solution are established by taking the following initial condition into account:

$u(x, 0)=f(x) e^{-\frac{B}{2} x}=\sum_{n=1}^{\infty} A_{n} e^{-\frac{B}{2} x} \sin \left(w_{n}\left(\frac{x}{l}\right)\right)$ 
The coefficients $A_{n}$ for $n=1,2,3, \ldots$ are determined by the help of inner product with weighted function defined on $L^{2}[0, l]$ as $<u, v \geq \frac{2}{l} \int_{0}^{l} u(x) v(x) e^{B x} d x$ :

$A_{n}=\frac{2}{l}<e^{-\frac{B}{2} x} \sin \left(w_{n}\left(\frac{x}{l}\right)\right), f(x) e^{-\frac{B}{2} x}>=\frac{2}{l} \int_{0}^{l} \sin \left(w_{n}\left(\frac{x}{l}\right)\right) e^{-\frac{B}{2} x} f(x) e^{-\frac{B}{2} x} e^{B x} d x=$
$\frac{2}{l} \int_{0}^{l} \sin \left(\frac{n \pi x}{l}\right) f(x) d x$.

\section{Illustrative example}

Consider the following initial boundary value problem with Dirichlet boundary conditions:

$u_{t}=u_{x x}+u_{x}-u$,

$u(0, t)=0, u(2, t)=0$,

$u(x, 0)=-\sin (\pi x) e^{-\frac{1}{2} x}$,

the solution of which is accomplished as follows:

$u(x, t)=-e^{-\frac{1}{2} x} \sin (\pi x) e^{-\left(\pi^{2}+\frac{5}{4}\right) t}$,

where $0 \leq x \leq 2,0 \leq t \leq T$.

Now let us consider the following fractional initial boundary value problem with Dirichlet boundary conditions:

$D_{t}^{\alpha} u(x, t)=u_{x x}(x, t)+u_{x}(x, t)-u(x, t)$,

$u(0, t)=u(2, t)=0$,

$u(x, 0)=\sin (\pi x) e^{-\frac{1}{2} x}$,

where $0<\alpha<1,0 \leq x \leq 2,0 \leq t \leq T$.

It is clear from Eq. (30) that the series form of the solution is accomplished as follows:

$u(x, t ; \alpha)=\sum_{n=1}^{\infty} A_{n} e^{-\frac{1}{2} x} \sin \left(w_{n}\left(\frac{x}{2}\right)\right) E_{\alpha, 1}\left(-\left(1+\frac{w_{n}^{2}+1}{4}\right) t^{\alpha}\right)$,

where $w_{n}=n$.

Substituting $t=0$ into the general solution (38) and utilizing the initial condition (37), we have

$-\sin (\pi x) e^{-\frac{1}{2} x}=\sum_{n=1}^{\infty} A_{n} e^{-\frac{1}{2} x} \sin \left(w_{n}\left(\frac{x}{2}\right)\right)$.

The coefficients $A_{n}$ for $n=0,1,2,3, \ldots$ are determined by the help of the inner product as follows: 


$$
\begin{aligned}
A_{n}=<\sin \left(w_{n}\left(\frac{x}{2}\right)\right) e^{-\frac{1}{2} x},-\sin (\pi x) e^{-\frac{1}{2} x}> \\
=\int_{0}^{2} \sin \left(w_{n}\left(\frac{x}{2}\right)\right) e^{-\frac{1}{2} x}(-\sin (\pi x)) e^{-\frac{1}{2} x} e^{x} d x
\end{aligned}
$$

For $n \neq 2, A_{n}=0 . n=2$ we get

$$
A_{2}=-\int_{0}^{2} \sin ^{2}(\pi x) d x=-\int_{0}^{2}\left(\frac{1}{2}-\frac{\cos (2 \pi x)}{2}\right) d x=\left.\left(\frac{x}{2}-\frac{\sin (2 \pi x)}{4}\right)\right|_{x=0} ^{x=2}=-1
$$

Thus

$$
u(x, t ; \alpha)=-e^{-\frac{1}{2} x} \sin (\pi x) E_{\alpha, 1}\left(-\left(\pi^{2}+\frac{5}{4}\right) t^{\alpha}\right)
$$

The accuracy of the method can be observed that as the order $\alpha$ of fractional derivative tends to 1, the solution (41) tends to the solution (34). The graphics of solutions for Example and Problem (33) in 2D are given in Figure 1.

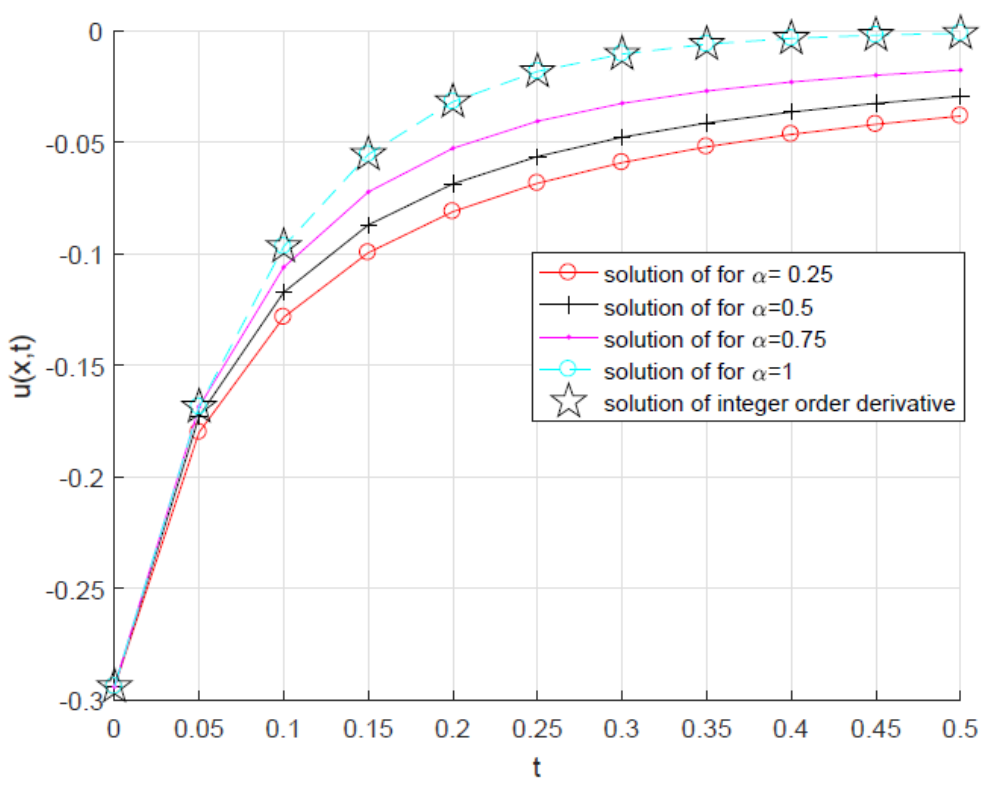

Figure.1. The graphics of solutions for Example in $2 \mathrm{D}$ at $\mathrm{x}=0.25$ for different $\alpha$.

As it is clear from the figure 1 that as $\alpha$ gets closer to 1 , the solution of fractional problem gets closer to the solution of integer order problem. It is also obvious that when the time variable $t$ is very small, the solutions of the fractional problem with any order $\alpha$ are close to each other and as time goes on discrepancy among the solutions becomes more obvious.

\section{Conclusion}

The main motivation of obtaining the series solution of time fractional initial boundary value problem including Dirichlet boundary conditions is accomplished by utilizing separation of variables method in terms of the solutions of related Sturm-Liouville 
eigenvalue problem. It is shown that this method works effectively with newly defined inner product. At the end of the this research, we reach the conclusion that the suitable weighted inner product allows us to construct the solution of any fractional differential equations without any difficulty.

Based on the analytic solution, we reach the conclusion that diffusion processes decays exponential with time until initial condition is reached. As $\alpha$ tends to 0 , the rate of decaying increases. This implies that in the mathematical model for diffusion of the matter which has small diffusion rate the value of $\alpha$ must be close to 0 . This model can account for various diffusion processes of various methods. For the future works similar problems with different boundary conditions are taken into consideration.

\section{References}

[1] Cetinkaya, S., Demir, A. and Kodal Sevindir, H., The analytic solution of initial boundary value problem including time-fractional diffusion equation, Facta Universitatis Ser. Math. Inform, 35, 1, 243-252, (2020).

[2] Cetinkaya, S., Demir, A. and Kodal Sevindir, H., The analytic solution of sequential space-time fractional diffusion equation including periodic boundary conditions, Journal of Mathematical Analysis, 11, 1, 17-26, (2020).

[3] Cetinkaya, S. and Demir, A., The Analytic Solution of Time-Space Fractional Diffusion Equation via New Inner Product with Weighted Function, Communications in Mathematics and Applications, 10, 4, 865-873, (2019).

[4] Cetinkaya, S., Demir, A. and Kodal Sevindir, H., The Analytic Solution of Initial Periodic Boundary Value Problem Including Sequential Time Fractional Diffusion Equation, Communications in Mathematics and Applications, 11, 1, 173-179, (2020).

[5] Cetinkaya, S. and Demir, A., Sequential Space Fractional Diffusion Equation's solutions via New Inner Product, Asian-European Journal of Mathematics, (2020), doi:10.1142/S1793557121501217

[6] Cetinkaya, S. and Demir, A., Time Fractional Diffusion Equation with Periodic Boundary Conditions, Konuralp Journal of Mathematics, 8, 2, 337-342, (2020).

[7] Cetinkaya, S. and Demir, A., Time Fractional Equation with Non-homogenous Dirichlet Boundary Conditions, Sakarya University Journal of Science SAUJS, 24, 6, 1185-1190, (2020).

[8] Cetinkaya, S. and Demir, A., Diffusion Equation Including Local Fractional Derivatıve and Non-Homogenous Dirichlet Boundary Conditions, Journal of Scientific Reports-A, 45, 101-110, (2020).

[9] Cetinkaya, S. and Demir, A., Equation Including Local Fractional Derivative and Neumann Boundary Conditions, Kocaeli Journal of Science and Engineering, 3, 2, 59-63, (2020).

[10] Cetinkaya, S. and Demir, A., Solution of hybrid time fractional diffusion problem via weighted inner product, Journal of Applied Mathematics and Computational Mechanics, 20, 2, 17-27, (2021).

[11] Cetinkaya, S. and Demir, A., On Solutions of Hybrid Time Fractional Heat Problem, Bulletin of the Institute of Mathematics Academia Sinica New Series, 16, 1, 49-62, (2021). 
[12] Cetinkaya, S., Demir, A. and Kodal Sevindir, H., Solution of Space-TimeFractional Problem by Shehu Variational Iteration Method, Advances in Mathematical Physics, Article ID 5528928, (2021).

[13] Cetinkaya, S. and Demir, A., Sequential time space fractional diffusion equation including nonhomogenous initial boundary conditions, Tbilisi Mathematical Journal, 14, 2, 83-91, (2021).

[14] Bisquert, J., Interpretation of a fractional diffusion equation with nonconserved probability density in terms of experimental systems with trapping or recombination, Physical Review E, 72, 173-179, (2005).

[15] Aguilar, J.F.G. and Hernández, M.M., Space-Time Fractional DiffusionAdvection Equation with Caputo Derivative, Abstract and Applied Analysis, 2014, Article ID 283019, (2014).

[16] Nadal, E., Abisset-Chavanne, E., Cueto, E. and Chinesta, F., On the physical interpretation of fractional diffusion, Comptes Rendus Mecanique, 346, 581589, (2018).

[17] Yavuz, M. and Abdeljawad, T., 2020. Nonlinear regularized long-wave models with a new integral transformation applied to the fractional derivative with power and Mittag-Leffler kernel, Adv. Differ. Equ., 367, (2020).

[18] Jena, R.M., Chakraverty, S. and Yavuz, M., Two-Hybrid Techniques Coupled with an Integral Transformation for Caputo Time-Fractional Navier Stokes Equations, Progress in Fractional Differentiation and Applications, 6, 3, 201213, (2020).

[19] Yavuz, M., European option pricing models described by fractional operators with classical and generalized Mittag-Leffler kernels, Numerical Methods for Partial Differential Equations, (2020).

[20] Evirgen, F., Conformable Fractional Gradient Based Dynamic System for Constrained Optimization Problem, Acta Physica Polonica A, 132, 1066-1069, (2017).

[21] Yavuz, M., Characterizations of two different fractional operators without singular kernel, Mathematical Modelling of Natural Phenomena, 14, 3, Article number 302, (2019).

[22] Evirgen, F., Yavuz, M., Cattani, C., Atangana, A., Bulut, H., Hammouch, Z., Baskonus, H.M., Mekkaoui, T. and Agoujil, S., An alternative approach for nonlinear optimization problem with Caputo-Fabrizio derivative, In ITM Web of Conferences (Vol. 22, p. 01009), EDP Sciences, (2018).

[23] Sarp, Ü., Evirgen, F. and İkikardeş S., Applications of differential transformation method to solve systems of ordinary and partial differential equations, Balıkesir Üniversitesi Fen Bilimleri Enstitüsü Dergisi, 20, 2, 135156, (2018).

[24] Yavuz, M. and Özdemir N., Analysis of an epidemic spreading model with exponential decay law, Mathematical Sciences and Applications E-Notes, 8, 1, 142-154, (2020).

[25] Yavuz, M. and Özdemir N., Comparing the new fractional derivative operators involving exponential and Mittag-Leffler kernel, Discrete \& Continuous Dynamical Systems-S, 13, 3, 995-1006, (2020).

[26] Kilbas, A.A., Srivastava, H.M. and Trujillo, J.J., Theory and Applications of Fractional Differential Equations. Elsevier, Amsterdam, Holland, (2006).

[27] Podlubny, I., Fractional Differential Equations, Academic Press, San Diego, USA, (1999). 